\title{
Viewpoint: Range science and range management are com- plementary but distinct endeavors
}

\section{FREDERICK D. PROVENZA}

Range management and range science are complementary but distinct endeavors. Range management is an attempt to optimize returns from rangelands in combinations desired by and suitable for society through the manipulation of range ecosystems (Stoddart et al. 1975). As such, range management is a planning process in which alternative management options are exposed to the decision-maker's values, and the option with the highest value is selected. Range science is the body of scientific knowledge upon which range management should be based. As such, range science should be the set of concepts and ideas that agree or are consistent with how natural processes operate. Both are necessary for wise use of range resources. The purpose of this paper is to discuss the roles of planning and science in range management, to provide examples of biological processes important in range management, and to discuss the role of range science in understanding those processes.

\section{Planning and Science}

Planning and science are different kinds of decision making (Romesburg 1981). Planning examines alternative images of a future possible world and selects the image with the highest value. The images in planning are composed of scientific knowledge, common sense, rule-of-thumb knowledge, untested theories, and hunches. Managers must plan with the best knowledge and thought at hand, regardless of their true value. Indeed, in many cases the planning involved in range management is based on common sense, rule-of-thumb knowledge, hunches, and untested theories, rather than scientific knowledge of biological processes.

Science exposes alternative theories to facts and selects the theory that agrees most closely with the facts. Of the 3 main methods of science, range scientists rely primarily on induction, to a limited extent on retroduction, and rarely on hypotheticodeduction (see review in Romesburg 1981). Lack of the use of retroduction and hypothetico-deduction to study the processes of most importance to range management has resulted in the lack of a conceptual and scientific basis for range management.

Induction is useful for finding laws of association between classes of facts. For example, if we observe over many trials that herbivores prefer to select green rather than dead plant parts, we are using induction if we declare a law of association. Induction has a limitation: it can only give knowled ge about possible associations among classes of facts. Induction can be useful in planning, provided the associations always hold, but it cannot give knowledge about the processes of nature. Hence, induction can be used repeatedly without explaining "how?" or "why?". When we ask "how?" or "why?" we are asking for an explanation, an abstract process that provides a reason for the facts.

Retroduction is useful for finding research hypotheses that are explanations for facts. For example, if we observe herbivores ingesting the most nutritious plant parts available on a range and our best guess for the reason for this behavior is that herbivores can relate the tastes of foods with their gastrointestinal consequences, we would be using retroduction to provide an explanation (research hypothesis) for the observed facts relating to the process of diet selection. Retroduction is essential for elucidating alternative research hypotheses, but retroduction alone is not a reliable source of knowled ge because alternative explanations can often be

\footnotetext{
Author is with the Department of Range Science, Utah State University 84322-5230. Published with the approval of the director, Utah Agr. Exp. Sta. as journal paper 3788 .
}

given for the same set of facts.

Hypothetico-deduction complements retroduction by subjecting alternative explanations to experimental verification. Starting with research hypotheses, predictions are made about other classes of facts that should be true if the research hypotheses are actually true. For example, one way to explain the preference of herbivores for some foods over others is to argue that preferred foods are immediately pleasing to the senses of taste, smell, and touch (Provenza and Balph 1990). An alternative explanation is that herbivores develop preferences for or aversions to foods as a result of their postingestive effects, and that taste and odor primarily enable animals to discriminate among different food items (Provenza and Balph 1990). To test these alternative explanations, the taste of a flavor could be paired with gastrointestinal consequences that are either positive or negative. The hypothesis that herbivores select food based on gastrointestinal consequences is supported if herbivores subsequently form preferences for or aversions to the flavor. If experiments are well-designed and carefully controlled (Platt 1964, Hurlbert 1984), the hypothetico-deductive method of science can evaluate the reliability of the research hypotheses generated by retroduction, and is the primary means of increasing the reliability of knowledge about natural processes.

\section{Processes Important in Range Management}

Many biological processes are important in range management. Plant autecology and synecology, as well as diet and habitat selection by herbivores, are of particular importance to grazing management. I use these as examples of processes that we must understand if we are to manage rangelands wisely.

Plant autecology is the study of a single organism or of a single species. Its importance to management lies in its ability to provide insights into characteristics that enable plants to tolerate or avoid disturbances such as grazing, cutting. and fire. Historically, much effort has gone into describing the responses of different plant species to factors such as season, intensity, and frequency of grazing (Stoddart et al. 1975). Genetic variation among and within plant species, as well as soil moisture and nutrient status and season, intensity, and frequency of disturbance, affect the ability of plants to tolerate or avoid grazing. To the extent that we can understand the mechanisms that underlie tolerance and avoidance, we can better manage rangelands (Caldwell 1984, Malechek et al. 1986, Bryant et al. 1987). Thus, range scientists must determine how and why plants tolerate or avoid disturbances.

Plant synecology is the study of the interactions among different plant species within plant communities. The importance of synecology to grazing management lies in its ability to predict changes in the abundance of different plant species as a result of management practices (Stoddart et al. 1975). Historically, much scientific effort has gone into describing existing vegetation and changes in vegetation. The concepts of range site and range condition and trend have developed as an outgrowth of these efforts (Stoddart et al. 1975). Future scientific endeavors must be directed at developing the conceptual and experimental basis for understanding the dynamic nature of plant population and community level processes to determine how and why vegetation exists as it does, and to relate the results to spatial and temporal scales appropriate for management (Archer and Tieszen 1986, Westoby et al. 1989). Such research will lead to important insights into the structure and function of plant communities, and enhance the abilities of range 
managers to intervene in ways that are wise.

Diet selection by herbivores affects both the production of herbivores and range condition. Animal nutrition depends on diet selection, as does the relative abundance of different plant species on rangelands (Stoddart et al. 1975). Research on diet selection has described the physical and chemical characteristics of plant species herbivores select and led to recommendations on when to graze and when to supplement on rangelands. It has not, however, provided understanding of how or why herbivores select some plant species and avoid others. To the extent that we can understand how and why herbivores select or avoid the plant species they do, we increase our potential to manipulate diet selection. Learning apparently plays a major role in the process of diet selection by herbivores (Provenza and Balph 1990, Provenza et al. 1990). If so, discovering how herbivores learn could let managers manipulate diet selection to increase use of supplements, feedlot rations, and unpalatable plant species, and to decrease use of poisonous plants, seedlings in forest plantations, and tree seedlings in orchards and conifer plantations (Provenza and Balph 1987).

Habitat selection by herbivores affects both the production of herbivores and range condition. Herbivores' production is affected because carrying capacity is dependent on animal dispersion. Range condition improves when herbivores disperse widely, and declines when they overutilize locations such as riparian zones. Grazing of public lands has become an increasingly contentious issue in the West, one that is likely to persist as a coalition of recreational users and environmentalists draws strength from a burgeoning urban population. The foraging behavior of livestock often raises the ire of recreational users of the same lands. One problem is that cattle and sheep tend to prefer the lush vegetation next to streams, a habit which can lead to overuse of these highly visible, ecologically sensitive areas. The grazing habits of livestock might be malleable enough that they can be trained to graze elsewhere. Different subgroups of herbivores differ in use of the same range, apparently learn habitat preferences, and transfer these preferences from generation-to-generation (Hunter and Milner 1963, Key and MacIver 1980, Zimmerman 1980, Roath and Krueger 1982). It might be possible to select animals that utilize upland habitats and cull those that favor riparian areas, thus enhancing dispersion on rangelands (Provenza and Balph 1987). We will not understand why herbivores use areas of the range differentially, however, if researchers continue to describe how factors such as temperature, relative humidity, forage availability, water location, and topography are correlated with affect the distribution of herbivores (Stoddart et al. 1975).

\section{The Role of Range Science}

As a science matures, it passes through several stages (Wiegert 1988). In the beginning, the science is largely descriptive and concern rests with determining what is there. During this stage the method of induction is used to establish laws of association between classes of facts. Once a large body of fact has accumulated, much energy is devoted to seeking order and pattern in the facts. Scientists then become more concerned with how things are arranged and how they function. Finally, scientists endeavor to explain why natural processes function as they do. During these latter 2 stages of development, the methods of retroduction and hypothetico-deduction are used extensively. It is time for range science to make the transition from the what to the how and why stages of development.

Traditionally, range scientists have described components of range ecosystems in an attempt to provide information for managers. This has been an extremely important first step in the development of range science, and most management recommendations are currently based on information generated by such efforts.
Nonetheless, it is often difficult to differentiate the role of the manager (planner) from that of the researcher (scientist), because researchers are often more intent on solving problems and providing management recommendations than on providing fundamental understanding of process important in range management.

An important role for range scientists now and in the future is to provide the scientific knowledge upon which planners can manage rangelands, and to a lesser extent to conduct research that in essence attempts to plan for the planners. Range scientists can no longer afford to describe and monitor rangelands in an attempt to plan for range managers. This is not to say that management is not important or that range scientists should not be involved in range management. Rather, scientists and managers have separate roles to play in wise use of natural resources. Scientists should be concerned with understanding the processes of nature that are important for management of natural resources; managers should use that understanding as the basis for managing rangelands.

If scientists continue to focus on solving problems, range as a discipline will be dead. Without a thorough understanding of the biological processes on which to base management, range managers have no more basis for decision making than do politically active special-interest groups. Range scientists must thoroughly understand the biological processes underlying range management to provide range managers with a firm basis for their decisions, and to provide them with credibility. If not, management of rangelands will be based on findings from disciplines that do have a firm scientific basis.

To develop scientifically, a discipline must have a conceptual basis. Conceptual models provide a focal point for research that is designed to understand processes in nature, and they help us organize the vast number of facts and observations related to processes. A discipline without a conceptual basis is like a boat without oars. Several factors are important if there are to be conceptual bases for the many biological facets of range science. First, range scientists must develop conceptual models of how we think important biological processes operate. Second, we must use retroduction to develop numerous alternative explanations for our conceptual models. Third, we must use hypothetico-deduction to test the alternative explanations. Fourth, we cannot make any assumptions about how or why processes, operate; rather, we must think of alternative explanations for every facet of every process, and we must design experiments that eliminate those explanations that are inaccurate. No stone can be left unturned. This will facilitate the movement of range science from the what to the how and why stages of development.

Range science is an integrative discipline. As such, range scientists are in an ideal position to organize multidisciplinary research. Indeed, the processes important to range scientists and managers can only be studied by drawing upon expertise from many disciplines. Scientists from other disciplines are interested in pursuing questions that interest range scientists, and range scientists should serve as a focal point for this kind of research. Thus, for example, the study of diet selection will involve disciplines as diverse as as natural products chemistry, animal physiology, pharmacology, toxicology, psychology, nutrition, and neural biology to name a few. Range scientists should provide the leadership in developing a strong conceptual basis for processes that are important for range management.

\section{Conclusion}

The role of contemporary range scientists is to develop an understanding of the processes that are important for the wise management of rangelands. Clearly, in some cases there is information available on the structure and functionining of ecosystems that is simply not being used in management, either because the informa- 
tion is relatively new and has not yet been incorporated into management programs or because managers do not know how to apply the information. In such cases, the problem is not so much that the science is lacking, but that the pure science has not been translated into practical application. It is equally true, however, that range scientists have not endeavored to understand processes that are important for the management of rangelands through careful analyses of the biological systems and processes. To provide a scientific basis for the management of rangelands will require research to understand the significant biological process, and research to apply that understanding to development of new technologies and management. The next major advances in range management will occur when researchers turn their attention from describing what occurs on rangelands to understanding the hows and whys of biological processes important to range management. As we do, the titles of our textbooks will change from "Principles of Range Management," to "Principles of Range Science and Their Application to Range Management."

\section{Literature Cited}

Archer, S.R., and L.L. Tieszen. 1986. Plant response to defoliation: hierarchical considerations. p. 45-59. In: 0 . Gudmundsson (Ed.) Grazing Research at Northern Latitudes. Plenum Press, New York.

Bryant, J.P., F.D. Provenza, and A. Gobena. 1987. Environmental controls over woody plant chemical defenses: implications for goat management. p. 1005-1034 In: O.P. Santana, A.G. da Silva and W.C. Foote (Eds.) Proc. IV Internat. Conf. on Goats. Departmento de Difusao de Technologia. Brazilia, Brazil.

Caldwell, M.M. 1984. Plant requirements for prudent grazing. p. 117-152. In: Developing Strategies for Rangeland Management. Westview Press, Boulder.
Hunter, R.F., and C. Milner. 1963. The behavior of individual, related and groups of south country Cheviot hill sheep. Anim. Behav. 11:507-513.

Hurlbert, S.H. 1984. Pseudoreplication and the design of ecological field experiments. Ecol. Monogr. 54:187-211.

Key, C., and R.M. MacIver. 1980. The effects of maternal influences on sheep: breed differences in grazing, resting and courtship behavior. Appl. Anim. Ethol. 6:33-48.

Malechek, J.C., D.F. Balph, and F.D. Provenza. 1986. Plant defense and herbivore learning: their consequences for livestock grazing systems. p. 193-208. In: O. Gudmundsson (Ed.) Grazing Research at Northern Latitudes. Plenum Press, New York.

Platt, J.R. 1964. Strong inference. Science 146:347-353.

Provenza, F.D., and D.F. Balph. 1987. Diet learning by domestic ruminants: theory, evidence and practical implications. Appl. Anim. Behav. Sci. 18:211-232.

Provenza, F.D., and D.F. Balph. 1990. Applicability of five diet-selection models to various foraging challenges ruminants encounters. p. 423-459. In: R.N. Hughes (Ed.) Behavioural Mechanisms of Food Selection. NATO ASI Series G: Ecological Sciences, Vol. 20. Springer-Verlag, Berlin, Heidelberg.

Provenza, F.D., J.A. Pfister, and C.D. Cheney. 1990. Mechanisms of learning in diet selection with reference to phytotoxicosis in herbivores. J. Range Manage. accepted.

Roath, L.R., and W.C. Krueger. 1982. Cattle grazing and behavior on a forested range. J. Range Manage. 35:332-338.

Romesburg, H.C. 1981. Wildlife science: gaining reliable knowledge. J. Wildl. Manage. 45:293-313.

Stoddart, L.A., A.D. Smith, and T.W. Box. 1975. Range Management. McGraw-Hill, New York.

Westoby, M., B. Walker, and I. Noy-Meir. 1989. Opportunistic management for rangelands not at equilibrium. J. Range Manage. 42:266-274.

Wiegert, R.G. 1988. Holism and reductionism in ecology: hypotheses, scale and systems models. Oikos 53:267-269.

Zimmerman, E.A. 1980. Desert ranching in Central Nevada. Rangelands 2:184-186.

Your Computer, helpful though it be, can never eliminate the need for a good personal library of professional publications. Contact the Society headquarters for a list of available publications on the art and science of range management. Write to 1839 York Street, Denver, Colorado 80206 or call (303) 355-7070. 